\title{
Study on the Production Technology, Elasticities and Market Structure Impact on Profit Formation*
}

\author{
Jian Wang ${ }^{1 \#}$, Xuejun Zheng ${ }^{2}$ \\ ${ }^{1}$ College of Economics and Trade, Agricultural University of Hebei, Baoding City, China \\ ${ }^{2}$ College of Foreign Language, Agricultural University of Hebei, Baoding City, China \\ Email: "wangjian@hebau.edu.cn
}

Received July 5, 2012; revised August 10, 2012; accepted August 20, 2012

\begin{abstract}
The size of the profit in a firm or a production system not only depends on the quantity of inputs and outputs, but also depends on the market structure that means the market is perfect competition or imperfect competition. In general, the relationship between output and inputs can be defined as the production structure, which is usually decided by production technology. Therefore, under the market economy system, the production structure regulation has to follow the market structure variation. Here we assume that production technology is a C-D function, and then to determine the effects of different market structures, which we find, they are in close contacted with both production and market structures, especially some variations of elasticities. Through out a series of deduction and equilibrium analysis, the restricted conditions of the maximum profit have been found. Therefore, the consequences show that the values of elasticities have taken an important role in profit obtained for producer, the profits in a perfect competition market hardly depends on market demand elasticity, in which production elasticity requires rather small. However, in the imperfect competition market, monopoly make both price of demand and production elasticities impact on the profit. Those also prove that market monopoly factors make production lose efficiency, or lead to the market failure. In the actual process of production and management, production elasticities and related market information should be strengthened for measurement, which will be useful for analysis price fluctuation risk and management decision.
\end{abstract}

Keywords: Elasticity; Profit Function; Supply \& Demand Function; Homogeneous of Degree H

\section{Introduction}

This study is about the production, market structure and rules of revenue. Production technology often restricts the profits obtained by producers. Here mainly refers to the technical constraints of production elasticity. The technical restriction is usually a production structural problem, when considering the issue occurred in the market and market structure will be in close contact with it. In the production process, technology determines the conversion of material and market structure makes this transition become more complicated. Although these problems have been concerned by economists many years ago, such as Harold Hotelling (1929), P. A. Samuelson (1947), Jan Tinbergen (1959), Ragnar Frisch (1965), R. Shephard (1970, 1981), Thomas J. Lutton and W. Erwin Diewert (1982), Hal R. Varian (1984, 1997), etc. These theories may include the production function, theory of market and profit, and so on. However, many problems generally exist in reality, which need to prove their seri-

*This paper is supported by China social science university humanity project (No. 12YJAZH138).

${ }^{\#}$ Corresponding author. ousness in theory and give more intuitive explanation. So that we discuss those problems beginning with a homogeneous production function defined by the Hal R. Varian (1984, p. 179), and attempt to demonstrate these issues clearly.

\section{Definition of Production Function}

The Cobb-Douglas technology describes can easily be extended to the case of $m$ inputs. A generalized C-D function for a production process can be defined as following [1].

$$
\begin{array}{r}
y=f(x)=A \cdot \prod_{i=1}^{m} x_{i}^{b_{i}}(i=1,2, \cdots m) \\
\text { or } \quad \log y=\log A+\sum_{i=1}^{m} b_{i} \cdot \log x_{i} .
\end{array}
$$

Here, $\mathrm{x}=\left(\mathrm{x}_{1}, \mathrm{x}_{2}, \mathrm{~L}, \mathrm{x}_{\mathrm{m}}\right)>0$ that is a vector with $\mathrm{m}$ dimensional input factors. $y>0$ is a single output of the production, and $\mathrm{f}$ is the function with twice differenttiable and continuous. That A means technical coefficient is used to keep in constant. $b_{i}$ is also a quantity of con- 
stant, which usually indicates the elasticity of production with related input factor of $\mathrm{x}_{\mathrm{i}}$, here

$$
\mathrm{b}_{\mathrm{i}}=(\partial \mathrm{y} / \mathrm{y}) /\left(\partial \mathrm{x}_{\mathrm{i}} / \mathrm{x}_{\mathrm{i}}\right)=\left(\partial \mathrm{y} / \partial \mathrm{x}_{\mathrm{i}}\right) /\left(\mathrm{y} / \mathrm{x}_{\mathrm{i}}\right) .
$$

Therefore, $y=f(x)$ is strictly quasi-concave and positively with homogenous of degree $h$ which respect to $x^{*}$ according to the significance of its economic definition. Here, $h$ can be defined as scale elasticity, so that $h=\sum b_{i}$ for all $x$. If there is a $t>0$, which makes all $x$ time $t$, then we find $y_{t}=f(t x)=t^{h} f(x)=t^{h} y$, it is easy to be proved:

Let us define the scale elasticity as

$$
\mathrm{h}=\frac{\Delta \mathrm{y} / \mathrm{y}}{\Delta \mathrm{t} / \mathrm{t}} \text {. }
$$

Use $\Delta t / t=\Delta x_{i} / x_{i}$ to make the total differentiation

$$
\begin{aligned}
\Delta y & =\sum_{i=1}^{m} \partial f / \partial x_{i} \cdot \Delta x_{i}=\sum_{i=1}^{m} b_{i} \cdot A \cdot \prod_{i=1}^{m} x_{i}^{b_{i}-1} \cdot x_{i} \\
& =\sum_{i=1}^{m} b_{i} A \prod_{i=1}^{m} x_{i}^{b_{i}} \cdot \Delta x_{i} / x_{i}=y \cdot \Delta t / t \cdot \sum_{i=1}^{m} b_{i},
\end{aligned}
$$

We get scale elasticity

$$
\frac{\Delta \mathrm{y} / \mathrm{y}}{\Delta \mathrm{t} / \mathrm{t}}=\sum_{\mathrm{i}=1}^{\mathrm{m}} \mathrm{b}_{\mathrm{i}}=\mathrm{h} \text {. }
$$

\section{Profit Function}

\subsection{Profit Function Definition}

Suppose the study refers to the market system, the market prices have to be decided by demand and supply. It is well known that production and management decision pursuits economic profit. The equilibrium analysis generally discusses how to decide the price, and to determine the optimal input or output. Thus, let $\omega=\left(\omega_{1}, \omega_{2}, \cdots, \omega_{\mathrm{m}}\right)$ $>0$ to present the price of input factors, and $\mathrm{p}$ as the price of single input. In this case, a profit function can be given as the following [2].

$$
\pi=\mathrm{p} \cdot \mathrm{y}-\omega \cdot \mathrm{x}=\mathrm{p} \cdot \mathrm{y}-\sum_{\mathrm{i}=1}^{\mathrm{m}} \omega_{\mathrm{i}} \cdot \mathrm{x}_{\mathrm{i}}
$$

It is easy to prove the following two lemmas by (2) $y=\partial \pi / \partial p$ (Hotelling); $x_{i}=-\partial \pi / \partial \omega_{i}$ (Shephard).

\subsection{Profit Maximization}

The profit maximization requires determining the inputs value of $\mathrm{x}^{*}>0$, which make that

$$
\pi\left(\mathrm{p}, \omega, \mathrm{x}^{*}\right)>\pi(\mathrm{p}, \omega, \mathrm{x}) \text { for all } \mathrm{p}>0, \omega>0, \mathrm{x}>0 .
$$

In general, during the analysis of profit maximization the factors selection are used to be endogenous variables, but prices $(p, \omega)$ and technologies are used to be exogenous variables. Therefore, to obtain Max $\pi$ that means the first order conditions has to be deviated by the defined profit function and production function. When we consider to pursuit the optimal profit in the product market, we should use Formula (2), let $\partial \pi / \partial \mathrm{x}_{\mathrm{i}}=0$ to be the first order condition.

$$
\begin{aligned}
& \partial \pi / \partial x_{i}=p \cdot \partial y / \partial x_{i}+y \cdot \partial p / \partial y \cdot \partial y / \partial x_{i}-\omega_{i}=0 . \\
& \text { for all } i=1,2, \cdots, m
\end{aligned}
$$

Thus we can obtain [3]

$$
\begin{aligned}
& \mathrm{p} \cdot \partial \mathrm{y} / \partial \mathrm{x}_{\mathrm{i}} \cdot(1+\partial \mathrm{p} / \partial \mathrm{y} \cdot \mathrm{y} / \mathrm{p})-\omega_{\mathrm{i}} \\
& =\mathrm{p} \cdot \partial \mathrm{y} / \partial \mathrm{x}_{\mathrm{i}} \cdot\left(1+1 / \varepsilon_{\mathrm{p}}\right)-\omega_{\mathrm{i}}=0 .
\end{aligned}
$$

Here, $\varepsilon_{\mathrm{p}}=\frac{\partial \mathrm{y} / \mathrm{y}}{\partial \mathrm{p} / \mathrm{p}}$

Here, $\varepsilon_{\mathrm{p}}<0$ is defined as the demand price elasticity of product $\mathrm{y}$. Especially, in perfect competition market when the producer is a price taker that $\left|\varepsilon_{\mathrm{p}}\right| \rightarrow \infty$ must be required. However, in the market of imperfect or monopoly $\left|\varepsilon_{\mathrm{p}}\right|>1$ will be the requirement. Because,

$$
\mathrm{p} \cdot \partial \mathrm{y} / \partial \mathrm{x}_{\mathrm{i}} \cdot\left(1+1 / \varepsilon_{\mathrm{p}}\right)=\omega_{\mathrm{i}}>0
$$

is required according to properties of optimal profit. That means $\mathrm{y}$ is increasing in $\mathrm{x},(\mathrm{p}, \omega)>0$, which makes $\left|\varepsilon_{\mathrm{p}}\right|>1$. Therefore, Formula (3) will be the condition of profit maximization in monopoly market, which can be written as following:

$$
\partial \mathrm{y} / \partial \mathrm{x}_{\mathrm{i}} \cdot\left(1+1 / \varepsilon_{\mathrm{p}}\right)=\omega_{\mathrm{i}} / \mathrm{p} .
$$

Considering Formula (1), using first-order partial derivatives we obtain $\partial y / \partial x_{i}=y b_{i} / x_{i}$, to combine it with Formula (4), we get input set $\mathrm{x}^{*}$ as a solution for Max $\pi$ in different markets at Formula (5):

$$
x_{i}^{*}=\left\{\begin{array}{l}
p \cdot y \cdot b_{i} / \omega_{i} \\
p \cdot y \cdot\left(1+1 / \varepsilon_{p}\right) \cdot b_{i} / \omega_{i}
\end{array}\right.
$$

In generally, in the perfect competition market we have to determine the input $x_{i}^{*}$ by (5-1), but in the imperfect market we have to determine the input $x_{i}^{*}$ by $(5-2)$. Because of $\left(1+1 / \varepsilon_{\mathrm{p}}\right)<1$ in monopoly market, input $\mathrm{x}$ is usual less than it in perfect competition market.

If a maximum profit relies on the optimal input vector $x^{*}$, it is easy for us to use Formula (5) to find $\pi\left(\mathrm{p}, \omega, \mathrm{x}^{*}\right)$, for all $\mathrm{p}>0, \omega>0, \mathrm{x}>0$, with Formula (2).

$$
\begin{aligned}
\pi^{*} & =\pi\left(p, \omega, x^{*}\right)=p \cdot y-\omega \cdot x^{*} \\
& =p \cdot y-\sum_{i=1}^{m} \omega_{i} \cdot x_{i}^{*} \\
& =\left\{\begin{array}{l}
p \cdot y \cdot(1-h) \\
p \cdot y \cdot\left[1-\left(1+1 / \varepsilon_{p}\right) \cdot h\right]
\end{array}\right.
\end{aligned}
$$

The important knowledge has been illustrated by Formula (6), basic information is about elasticity. In addition 
to the revenue $\mathrm{p} \cdot \mathrm{y}$, there is more important economic signal that is the elasticity of production $h$. That shows the stability of production or the sensitivity of input factors in production process will affect the quantity of profit directively, particularly in the production function the value of $h$ needs to be measured and well controlled.

- Certainly most of markets structures belong to imperfect competition, monopoly factors in real market are existed generally. The influence of monopoly in Formula (6) is indicated by price elasticity of demand $\varepsilon_{\mathrm{p}}$. Therefore, $\left|\varepsilon_{\mathrm{p}}\right|>1$ is a basic requirement that postulated to be reached in market of monopoly production. To compare those two kinds of markets for $\pi^{*} \geq 0$, which requires $\mathrm{h} \leq 1$, but this only related to the process of production, however, the sensitivity of market demand variation with $\mathrm{p}$ will be measured by $\left(1+1 / \varepsilon_{\mathrm{p}}\right)$. So that, $0<\left(1+1 / \varepsilon_{\mathrm{p}}\right)<1$ is the normal case of imperfect competition market according to Formula (4). Further discussion on the issues will be launched as following.

\section{Supply and Demand Functions}

\subsection{The Supply Function}

If we take the results in Formula (5) into Function (1), a supply function of producer for optimal profit can be obtained. This result shows in Formula (7), which in different markets the issues will be different.

There are many properties in Formula (7), where (7-1) is perfect competition market, and (7-2) is non perfect competition market. Such as the output $\mathrm{y}^{*}$ is monotonically increasing with both price $\mathrm{p}$ and $\left|\varepsilon_{\mathrm{p}}\right|$, the price elasticity of supply function of the output that indicated by $h$ should be limited to small one, because if $h /(1-h)>1$ requires $h<1 / 2$. [4] Moreover, in mono- poly market also requires $\mathrm{h}<1 / 2$, and $1>\left(1+1 / \varepsilon_{\mathrm{p}}\right)>0$ become necessary.

\subsection{The Demand Function}

Further more, we can derivative demand function of the input factors by (5) and (7), which are the optimal results. We get the Formula (8):

As a well known property for demand function has homogenous of degree 0 in $\mathrm{p}, \omega$, which is easy to demonstrate in Formula (8). There is

$\mathrm{x}^{*}=\mathrm{x}(\mathrm{tp}, \mathrm{t} \omega)=\mathrm{x}(\mathrm{p}, \omega)$, for a given $\mathrm{t}>0$.

\section{Conclusions}

Now we can use the above derived results, only when the second order conditions $\partial^{2} \pi / \partial \mathrm{x}_{\mathrm{i}}^{2}<0$ are satisfied, we can obtain the optimal profit function.

$$
\pi^{*}=\pi\left(\mathrm{p}, \omega, \mathrm{x}^{*}\right)=\pi\left(\mathrm{p}, \omega, \mathrm{y}^{*}\right)=\pi^{*}(\mathrm{p}, \omega),
$$

for all $p>0, \omega>0$ and $(i=1,2, \cdots m)$. Then

The consequence of Formula (9) tell us that the optimal inputs $\mathrm{x}^{*}$ can bring an optimal level of output $\mathrm{y}^{*}$, which make maximum profit function $\pi^{*}(p, \omega)$ as an endogenous variable, then market prices $(p, \omega)$ can be thought as exogenous variables. In the profit maximization model, price and technology are exogenous variables, and the factors of choice are endogenous variables, this view is consistent with Hal R. Valrian (1992, p. 203). Therefore, the properties of profit function $\pi^{*}(p, \omega)$ are easy to be proved herewith. [2]

1) Above profit function is nondecreasing in $p$ for output, nonincreasing in $\omega$ for inputs. If

$$
\mathrm{p}^{\prime} \geq \mathrm{p} \text { and } \omega^{\prime} \leq \omega, \text { then } \pi^{*}\left(\mathrm{p}^{\prime}, \omega^{\prime}\right) \geq \pi^{*}(\mathrm{p}, \omega) .
$$

$$
\begin{gathered}
\mathrm{y}^{*}=\mathrm{f}\left(\mathrm{x}^{*}\right)=\mathrm{A} \cdot \prod_{\mathrm{i}=1}^{\mathrm{m}}\left(\mathrm{x}_{\mathrm{i}}^{*}\right)^{\mathrm{b}_{\mathrm{i}}} \text { for all }(\mathrm{i}=1,2, \cdots, \mathrm{m})=\left\{\begin{array}{l}
{\left[\mathrm{A} \cdot \mathrm{p}^{\mathrm{h}} \cdot \prod_{\mathrm{i}=1}^{\mathrm{m}}\left(\mathrm{b}_{\mathrm{i}} / \omega_{\mathrm{i}}\right)^{\mathrm{b}_{\mathrm{i}}}\right]^{1 /(1-\mathrm{h})}} \\
{\left[\mathrm{A} \cdot \mathrm{p}^{\mathrm{h}} \cdot\left(1+1 / \varepsilon_{\mathrm{p}}\right)^{\mathrm{h}} \cdot \prod_{\mathrm{i}=1}^{\mathrm{m}}\left(\mathrm{b}_{\mathrm{i}} / \omega_{\mathrm{i}}\right)^{\mathrm{b}_{\mathrm{i}}}\right]^{1 /(1-\mathrm{h})}}
\end{array}\right. \\
\mathrm{x}_{\mathrm{i}}^{*}=\left\{\begin{array}{l}
\mathrm{p} \cdot \mathrm{y}^{*} \cdot \mathrm{b}_{\mathrm{i}} / \omega_{\mathrm{i}}=\left[\mathrm{A} \cdot \mathrm{p} \cdot\left(\mathrm{b}_{\mathrm{i}} / \omega_{\mathrm{i}}\right)^{1-\mathrm{h}} \cdot \prod_{\mathrm{i}=1}^{\mathrm{m}}\left(\mathrm{b}_{\mathrm{i}} / \omega_{\mathrm{i}}\right)^{\mathrm{b}_{\mathrm{i}}}\right]^{1 /(1-\mathrm{h})} \\
\mathrm{p} \cdot \mathrm{y}^{*} \cdot\left(1+1 / \varepsilon_{\mathrm{p}}\right) \cdot \mathrm{b}_{\mathrm{i}} / \omega_{\mathrm{i}}=\left[\mathrm{A} \cdot \mathrm{p} \cdot\left(1+1 / \varepsilon_{\mathrm{p}}\right)^{\mathrm{h}} \cdot\left(\mathrm{b}_{\mathrm{i}} / \omega_{\mathrm{i}}\right)^{1-\mathrm{h}} \cdot \prod_{\mathrm{i}=1}^{\mathrm{m}}\left(\mathrm{b}_{\mathrm{i}} / \omega_{\mathrm{i}}\right)^{\mathrm{b}_{\mathrm{i}}}\right]^{1 /(1-\mathrm{h})}
\end{array}\right. \\
\pi^{*}(\mathrm{p}, \omega)=\left\{\begin{array}{l}
\mathrm{p} \cdot \mathrm{y}^{*} \cdot(1-\mathrm{h}) \\
\mathrm{p} \cdot \mathrm{y}^{*} \cdot\left[1-\left(1+1 / \varepsilon_{\mathrm{p}}\right) \cdot \mathrm{h}\right]
\end{array}\right]\left\{\begin{array}{l}
{\left[\mathrm{A} \cdot \mathrm{p} \cdot \prod_{\mathrm{i}=1}^{\mathrm{m}}\left(\mathrm{b}_{\mathrm{i}} / \omega_{\mathrm{i}}\right)^{\mathrm{b}_{\mathrm{i}}}\right]^{1 /(1-\mathrm{h})} \cdot(1-\mathrm{h})} \\
{\left[\mathrm{A} \cdot \mathrm{p} \cdot\left(1+1 / \varepsilon_{\mathrm{p}}\right)^{\mathrm{h}} \cdot \prod_{\mathrm{i}=1}^{\mathrm{m}}\left(\mathrm{b}_{\mathrm{i}} / \omega_{\mathrm{i}}\right)^{\mathrm{b}_{\mathrm{i}}}\right]^{1 /(1-\mathrm{h})} \cdot\left[1-\left(1+1 / \varepsilon_{\mathrm{p}}\right) \cdot \mathrm{h}\right]}
\end{array}\right.
\end{gathered}
$$


2) $\pi^{*}(p, \omega)$ is homogeneous of degree one in prices. $\pi^{*}(\mathrm{t}, \mathrm{t} \omega)=\mathrm{t} \pi^{*}(\mathrm{p}, \omega)$ for $\mathrm{t}>0$.

$3)$ It is convex in $(p, \omega)$.

Let $\mathrm{p}^{\prime \prime}=\mathrm{t} \cdot \mathrm{p}+(1-\mathrm{t}) \cdot \mathrm{p}^{\prime}$, for $\mathrm{t} \in[0,1]$, then

$$
\pi^{*}\left(\mathrm{p}^{\prime \prime}\right) \leq \mathrm{t} \cdot \pi^{*}(\mathrm{p})+(1-\mathrm{t}) \cdot \pi^{*}\left(\mathrm{p}^{\prime}\right) .
$$

4) The profit function $\pi^{*}(\mathrm{p}, \omega)$ is continuous in (p, $\left.\omega\right)$, at least for $p>0, \omega \gg 0$, and $\pi^{*}$ is convergent conditional with $h<1 / 2 \ll\left|\varepsilon_{\mathrm{p}}\right|$.

5) In addition, we are able to demonstrate $\partial \mathrm{x}_{\mathrm{j}} / \partial \mathrm{x}_{\mathrm{i}}=\omega_{\mathrm{i}} / \omega_{\mathrm{j}}$ by Formula (4).

The classical economics suppose that a firm has completed information. A perfect market is able to utilize "a spontaneous invisible hand" to produce free action between the demand and the supply to realize market clear. The firm just like in a well planned system, the market is with perfect competition and the producer is a price taker. However, the ideal system is hardly existed, currently the existences of monopolies factors are very objective, and market information is general not enough according to the information economics. As a matter of fact, the firm usually makes optimal choice under different market structures. Imperfect market with uncompleted or asymmetric information is a general case. If an economy want to use "a visible hand" to play an efficient role, then the information and measurement from micro to macro become necessary in all the cases. Such as this study, if a firm considers optimal of its own profit, it has to analyze the market structure, and to measure the price and the production elasticities. That information collection should give the institutional arrangement and solve the issues of market to reduce uncertainty or avoid management risk, and so on.

\section{REFERENCES}

[1] H. R. Varian, "Microeconomic Analysis," 2nd Edition, W. W. Norton \& Co., Inc., New York, 1984.

[2] H. R. Varian, "Microeconomic Analysis," 3rd Edition, W. W. Norton \& Co., Inc., New York, 1992.

[3] J. Wang, “(M, E, I) Model as Multi-Input Production Function with Homogeneousness of Degree H," Anlyse de Systemes, Vol. 23, No. 4, 1997, pp. 45-49.

[4] J. M. Price, "Price Elasticities Implied by Homogeneous Production Functions," The Journal of Agricultural Economics Research, Vol. 45, No. 2, 1994, pp. 433-443.

[5] J. Tinbergen, "Production, Income and Welfare: The Search for an Optimal Social Order," Wheatsheaf Books, Brighton, 1985.

[6] J. Wang, "From Reducing Uncertainty to Feedback," Proceedings of the 2 nd International Conference on Information Science and Engineering, Vol. 4, 2010, pp. 28592863.

[7] J. M. Perloff, "Microeconomics," 4th Edition, Pearson Education, Inc., London, 2007. 